\title{
Superior mesenteric artery syndrome coexists with Nutcracker syndrome in a female: a case report
}

\author{
Ying Shi ${ }^{1,2^{*}} \mathbb{D}$, Guangya Shi ${ }^{3}$, Zhenyu $\mathrm{Li}^{4}$, Yanfang Chen ${ }^{1,2}$, Shaohui Tang ${ }^{1,2}$ and Wei Huang ${ }^{1,2^{*}}$
}

\begin{abstract}
Background: Superior mesenteric artery (SMA) syndrome, also known as Wilkie's syndrome or Benign duodenal stasis, is a rare benign disease. It could threaten the life if the manifestation is severe and the treatment is inappropriate. In the patients with SMA syndrome, the third portion (transverse part) of the duodenum is compressed externally between the SMA and abdominal aorta (AA) leading to duodenal stasis and gastrointestinal obstruction. SMA syndrome may rarely combine with Nutcracker syndrome when left renal vein (LRV) was compressed between SMA and AA.
\end{abstract}

Case presentation: A 32-year-old female patient presented with complaints of gradually severe bloating, epigastric pain, left flank ache, nausea and occasional vomiting of 1 month's duration. The epigastric and left flank ache was aggravated when the patient was supine and relieved in a prone or left lateral decubitus. The abdominal bloating was associated with early satiety. The vomiting always started $40 \mathrm{~min}$ after meal. The patient gave a history of urine stone with drotaverine hydrochloride tablets treatment for two weeks before the gastrointestinal symptoms arising. The patient had no significant surgical history, but had a rapid weight loss of approximately $10 \mathrm{~kg}$ with a body mass index (BMI) from $21 \mathrm{~kg} / \mathrm{m}^{2}$ to less than $18 \mathrm{~kg} / \mathrm{m}^{2}$ over the last two months. An abdominal examination revealed upper abdominal tenderness and distention. The urine routine examination showed no significant abnormality. The findings of initial blood tests and other laboratory investigations were unremarkable.

Conclusions: This case reports a female patient with SMA syndrome with Nutcracker syndrome predisposed by Antispasmodics. We highlight the importance of the combination therapy of long-term nutritional supporting and prokinetic agents. Rehabilitating practice after discharge is beneficial to reduce recurrence.

Keywords: Superior mesenteric artery, Nutcracker syndrome

\section{Background}

Superior mesenteric artery (SMA) syndrome, also known as Wilkie's syndrome or Benign duodenal stasis, is a rare benign disease. It has reported that the prevalence of SMA syndrome was approximately $0.0024-0.3 \%$ [1-3]. Although SMA syndrome is benign, it could threaten the life if the manifestation is severe and the treatment is inappropriate [4]. In the patients with SMA syndrome, the third portion (transverse part) of the duodenum is compressed externally between the SMA and abdominal aorta (AA) leading to duodenal stasis and gastrointestinal

\footnotetext{
* Correspondence: shiying@jnu.edu.cn; thuangw@jnu.edu.cn

'Department of Gastroenterology, The First Affiliated Hospital, Jinan

University, Guangzhou 510630, People's Republic of China

Full list of author information is available at the end of the article
}

obstruction [5]. The symptoms of SMA syndrome include acute or chronic episodic epigastric ache, bloating or vomiting, which associated with rapid growth in children and rapid weight loss in adults, particularly in young women [6,7]. Once the compression of left renal vein (LRV) was just happened by SMA and AA, the SMA syndrome may rarely combine with Nutcracker phenomenon [8]. Here, we report a case of SMA syndrome coexist with Nutcracker syndrome in a 32-year-old female who presented to our gastroenterology department with a 1-month history of epigastric ache, bloating and vomiting after meal. In this report, we will further discuss the possible predisposing factors and other information for this case.

(c) The Author(s). 2019 Open Access This article is distributed under the terms of the Creative Commons Attribution 4.0 International License (http://creativecommons.org/licenses/by/4.0/), which permits unrestricted use, distribution, and reproduction in any medium, provided you give appropriate credit to the original author(s) and the source, provide a link to the Creative Commons license, and indicate if changes were made. The Creative Commons Public Domain Dedication waiver (http://creativecommons.org/publicdomain/zero/1.0/) applies to the data made available in this article, unless otherwise stated. 


\section{Case presentation}

A 32-year-old female patient presented to the gastroenterology department of the First Affiliated Hospital, Jinan University, Guangzhou, China, in 2017 with complaints of gradually severe bloating, epigastric and left flank ache, nausea and occasional vomiting of 1 month's duration. The epigastric and left flank ache was aggravated when the patient was supine and relieved in a prone or left lateral decubitus. The abdominal bloating was associated with early satiety. The vomiting always began 40 min after meal. The patient provided a history of urine stone with oral drotaverine hydrochloride tablets treatment $40 \mathrm{mg}$ three times a day (tid) for two weeks before the gastrointestinal symptoms arising. The patient had no significant surgical history, but had a rapid weight loss of approximately $10 \mathrm{~kg}$ with a body mass index from $21 \mathrm{~kg} / \mathrm{m}^{2}$ to $18 \mathrm{~kg} / \mathrm{m}^{2}$ over the last two months. An abdominal examination revealed upper abdominal tenderness and distention. The urine routine examination showed no significant abnormality (no hematuria and proteinuria). There were no remarkable abnormalities during the initial blood tests and other laboratory investigations.

On performing a physical examination, her epigastric region was distended and tender to palpation. Contrastenhanced abdominal computed tomography (CT) demonstrated gastroduodenal dilatation (Fig. 1a). There was narrowing of the third portion of the duodenum compressed by SMA and AA, with a decreased aortomesenteric distance of $3.7 \mathrm{~mm}$ and a narrower aortomesenteric angle of less than 15 degrees, which suggested a diagnosis of SMA syndrome (Fig. 1b, arrow). In addition, the
LRV was compressed to $2 \mathrm{~mm}$ between SMA and AA (Fig. 1c, arrow), with a $12 \mathrm{~mm}$ dilatation in diameter (Fig. 1c, star), which formed a "bird beak sign" (Fig. 1c, arrow). Upper gastrointestinal double-contrast radiograph showed a vertical band of extrinsic compression (Fig. 2, arrow) on the mid transverse part of duodenum caused by SMA with proximal duodenal dilatation (Fig. 2, star). Gastroptosis was also observed by fluoroscopy. Colour Doppler indicated that the inside diameter of compressed stenosis of LRV was $1.4 \mathrm{~mm}$ on the left edge of AA, with $61 \mathrm{~cm} / \mathrm{sec}$ of the maximum blood flow velocity. The inside diameter of proximal dilatation site was $6.1 \mathrm{~mm}$, with $20 \mathrm{~cm} / \mathrm{sec}$ of the maximum blood flow velocity. Additionally, the angle between SMA and AA was approximately 13 degrees, and bilateral iliac vein flow was slow. Therefore, a diagnosis of SMA syndrome and Nutcracker syndrome was confirmed.

Nasogastric tube was placed for decompression. Fluid resuscitation with parenteral and enteral nutritional support was managed conservatively to improve weight gain. Considering the neuromuscular and motility function could be impaired by the disease, pharmacotherapy (Mosapride citrate dispersible tablets $5 \mathrm{mg}$ po tid) and physiotherapy (Functional gastrointestinal treatment apparatus) were treated to modulate the gastrointestinal motor function. Patient underwent a gastroduodenoscopy after the condition was relieved, revealing no intrinsic obstructions. Considering no significant abnormalities in renal function parameters and blood pressure, no special medical interventions were performed for the Nutcracker syndrome. One week later,
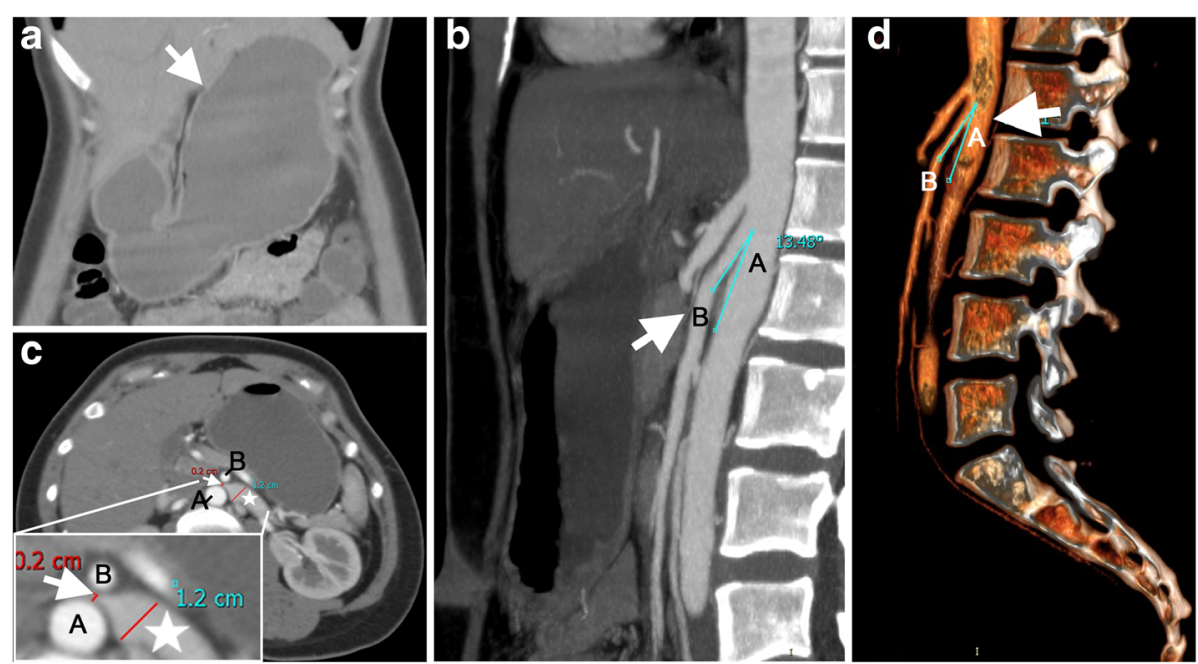

Fig. 1 CT imaging showing SMA syndrome and Nutcracker Syndrome. (a) Coronal view of gastroduodenal dilation (arrow). (b) Sagittal view of

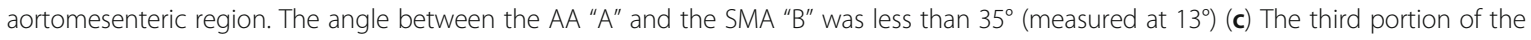
duodenum was compressed by the decreased aortomesenteric angle in the transverse plane. The compressed LRV between the AA " $A$ " and the SMA "B" was showed as arrow (bird beak sign). The dilation LRV was showed as star. The zoomed structures presented in the lower left. (d) Three-dimensional reconstruction of the AA "A" and the SMA "B" 


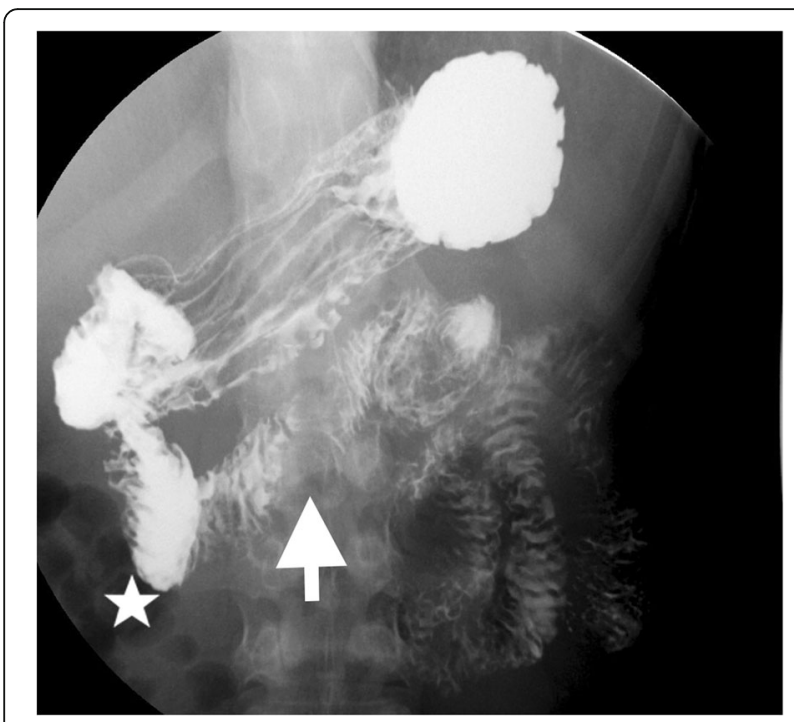

Fig. 2 Upper gastrointestinal series/Upper gastrointestinal doublecontrast radiograph. A vertical band of extrinsic compression (arrow) on the mid transverse part of duodenum compressed by SMA with proximal duodenal dilatation (star)

the patient was discharged and subsequently received family nutrition support treatment for six months.

\section{Follow-up}

BMI data were collected each week during the family nutrition support treatment (Fig. 3a), and BMI values gradually increased (Fig. 3b). However, in the fourth month, she suspended the family nutrition support and began to work. BMI quickly reduced, and the symptoms recurred including bloating, epigastric pain, left flank ache and nausea. During her second hospitalization, an abdominal examination revealed upper abdominal distention, and the urine routine examination showed hematuria. Nasal jejunal tube was placed and Enteral nutrition was provided for one week. After weight gain and hematuria disappeared, the patient discharged. Subsequently, the patient received family nutrition support treatment for six months, and BMI values fluctuated within the normal range $\left(18.8 \pm 0.13 \mathrm{~kg} / \mathrm{m}^{2}\right.$ to $19.1 \pm$ $\left.0.74 \mathrm{~kg} / \mathrm{m}^{2}\right)$.

\section{Discussion}

\section{Predisposing factors}

The SMA syndrome is due to the lack of retroperitoneal fat and lymphatic tissue, which support a protection from the compression by SMA [9]. A number of predisposing factors leading to the abnormally narrow angle between the proximal SMA and AA have been described. Rapid growth in children and exaggerated weight loss in adults were the most common factors. Others include poor motility of the digestive tract, malabsorption, cachexia, visceroptosis, abdominal wall laxity, peritoneal adhesions, retroperitional tumors and catabolic states. The patient we reported had a lanky body build and a history of episodic epigastric pain and bloating for 25 years. The stressful career made her loss almost $10 \mathrm{~kg}$ of weight within two months, which was considered to be one of the predisposing factors leading to the acute symptoms. Two weeks before the gastrointestinal symptoms arising this time, she took antispasmodics (drotaverine hydrochloride tablets, $40 \mathrm{mg}$ tid) for urine stone. However, antispasmodics may also cause

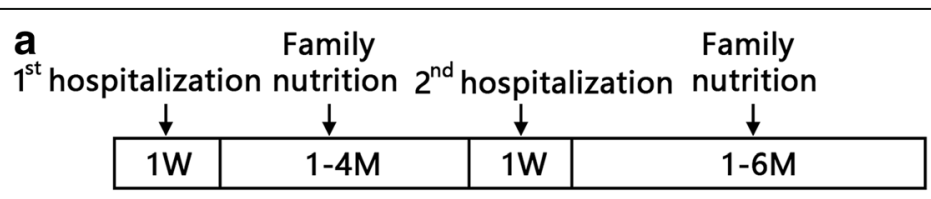

b

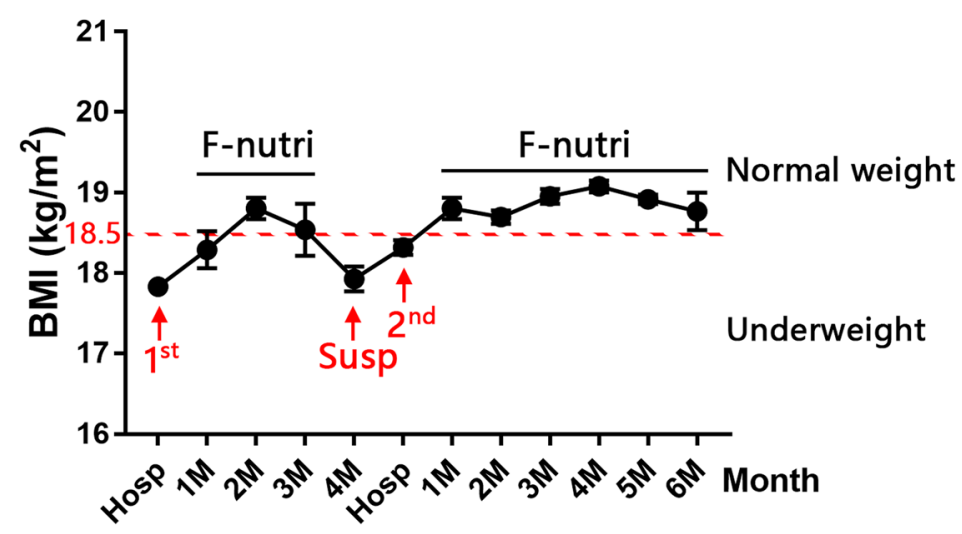

Fig. 3 Follow-up BMI data collection. (a) The timeline of the disease course in this case report. (b) The follow-up BMI data collection. Hosp: hospitalization, F-nutri: family nutrition support, Susp: suspend 
smooth muscle relaxation in gastrointestinal tract. We supposed that spasmolytic drugs leaded to the disorder of the gastrointestinal motility, which aggravated the symptoms of duodenal obstruction and stomach retention. However, the causal relationship between spasmolytic drugs and SMA syndrome still need to be clarified through retrospective studies or prospective clinical trials. Therefore, all of the histories made us infer that multiple and complicated predisposing factors triggered the clinical symptoms arising based on her congenital anomalous anatomic characteristics.

\section{Diagnosis}

\section{SMA syndrome}

Patients with the chronic, congenital SMA syndrome always have a lengthy and episodic history of abdominal complaints, such as epigastric bloating or anorexia. It is important to note that this condition is easily to be misdiagnosed as functional disorder or anxiety state, because the Gastrointestinal Endoscopy always display normal mucosa during the clinical diagnosis [10]. This female patient we reported had a history of episodic epigastric pain and bloating for 25 years, which was diagnosed as dyspepsia. Due to the intermittent exacerbating symptoms, she was suggested to fill in Hamilton Anxiety Scale once. Therefore, differential diagnosis is extremely important, since the misdiagnosis in this syndrome could be dangerous.

\section{Nutcracker syndrome}

The Nutcracker phenomenon may give rise to the Nutcracker syndrome in the presence of typical clinical manifestations with hematuria, proteinuria and left flank pain. This patient suffered from a left flank pain, without hematuria in the first hospitalization. Beside CT scan, the colour Doppler indicated the nutcracker phenomenon due to the compression of LRV and the abnormally small angle between SMA and AA. A transient hematuria occurred with a left flank pain during the second hospitalization, and disappeared after weight gain. Therefore, Nutcracker syndrome was diagnosed according to the imaging changes and clinical manifestations.

\section{"Radiation-free" alternatives}

The CT-scan was performed to screen the cause of abdominal pain. In order to confirm duodenal stasis and achieve a diagnosis of SMA syndrome, the upper gastrointestinal double-contrast radiograph was performed after then. However, alternative "radiation-free" imaging examination would be considered to avoid the radiation exposure, especially for the female patients of childbearing age. Ultrasonography (US) examination has been used in SMA syndrome diagnosis. It has been reported that abdominal US with power colour Doppler was performed for 3622 patients with dyspepsia and/or abdominal pain, revealing a significant reduction of AA [11]. SMA syndromes with Crohn's disease underwent magnetic resonance enterography (MRenterography, MRE) drinking contrast medium in the prone position during the examination, which showed a decrease of aortomesenteric distance and an interruption of the third portion of duodenum [12].

\section{Management \\ Conservative treatment}

Medical treatment may consist of nasogastric intubation for gastroduodenal decompression, reversal or removal of the precipitating factor and nutritional supplementation with hyperalimentation by jejunal feeding tube or peripherally inserted central catheter (PICC line). Prokinetic agents (such as Mosapride) or physiotherapy (such as functional gastrointestinal treatment apparatus) will be beneficial to modulate the gastrointestinal motor function. After the typical symptoms were relieved, small feeding and liquid diets would be available. Mobilization into the prone or left lateral decubitus position after eating should be practiced to relief duodenal decompression and improve gastric empty. The abdominal complaints will be improved after recovery of the lost weight.

\section{Surgical treatment}

Treatment of SMA syndrome initially involves conservative management. However, surgical intervention will be requited if medical treatment fails or the condition is severe [13]. The alternative operations mainly included open duodenojejunostomy and laparoscopic duodenojejunostomy. A prospective study in a single institution has been reported that SMA syndrome patients underwent duodenojejunostomy or performed a distal duodenum resection [1]. Laparoscopic duodenojejunostomy is considered to be feasible, safe, less morbid and effective for SMA syndrome compared with open surgery $[14,15]$. Even for SMA syndrome combined with Nutcracker syndrome due to severe weight reduction, weight gain and SMA syndrome was corrected by laparoscopic duodenojejunostomy [16].

\section{Rehabilitation}

Besides nutritional supporting [17] and decubitus position, the rehabilitating practice after discharge is also important to reduce recurrence. We recommend the rehabilitating practice after discharge, such as appropriate swimming, which is beneficial to enhance the abdominal wall and reduce the frequency of recurrence, especially for female patient. However, retrospective study of more cases, even the prospective clinical trials are still needed to assess the effectivity. 


\section{Conclusions}

This case reports a female patient with SMA syndrome with Nutcracker syndrome predisposed by Antispasmodics. We highlight the importance of the combination therapy of long-term nutritional supporting and prokinetic agents. Rehabilitating practice after discharge is beneficial to reduce the frequency of recurrence.

\section{Abbreviations}

AA: Abdominal aorta; BMl: Body mass index; CT: Contrast-enhanced abdominal computed tomography; LRV: Left renal vein; PICC: Peripherally inserted central catheter, SMA: Superior mesenteric artery

\section{Acknowledgements}

Not applicable.

\section{Funding}

The authors declare that they received no specific grant from any funding agency in the public, commercial or not-for-profit sectors.

\section{Availability of data and materials}

The datasets used and/or analyzed during the current study are available from the corresponding author on reasonable request.

\section{Authors' contributions}

YS and GYS assembled, analyzed and interpreted the patient's data and case presentation. ZYL read the Radiographic images and made the imaging diagnosis. YFC reviewed the literature. GYS, SHT and WH made the therapeutic strategies and treated the patient. YS and GYS wrote the manuscript. All authors read and approved the final manuscript.

\section{Ethics approval and consent to participate}

Not applicable.

\section{Consent for publication}

Written informed consent was obtained from the patient for publication of this case report and accompanying images.

\section{Competing interests}

The authors declare that they have no competing interests.

\section{Publisher's Note}

Springer Nature remains neutral with regard to jurisdictional claims in published maps and institutional affiliations.

\section{Author details}

${ }^{1}$ Department of Gastroenterology, The First Affiliated Hospital, Jinan University, Guangzhou 510630, People's Republic of China. ${ }^{2}$ The First Clinical Medical College, Jinan University, Guangzhou 510630, People's Republic of China. ${ }^{3}$ Department of Gastroenterology, The People's Hospital of Fujian Province, 350004 Fujian, People's Republic of China. ${ }^{4}$ Department of Radiology, The First Affiliated Hospital, Jinan University, Guangzhou 510630, People's Republic of China.

Received: 18 August 2018 Accepted: 14 January 2019

Published online: 23 January 2019

\section{References}

1. Ganss A, Rampado S, Savarino E, Bardini R. Superior mesenteric artery syndrome: a prospective study in a single institution. J Gastrointest Surg. 2018. https://doi.org/10.1007/s11605-018-3984-6. Accessed 5 Oct 2018

2. Merrett ND, Wilson RB, Cosman P, Biankin AV. Superior mesenteric artery syndrome: diagnosis and treatment strategies. J Gastrointest Surg. 2009;13(2):287-92.

3. Welsch T, Buchler MW, Kienle P. Recalling superior mesenteric artery syndrome. Digestive surgery. 2007;24(3):149-56.

4. Ugras M, Bicer S, Coskun FT, Romano E, Ekci B. Superior mesenteric artery syndrome: a rare but life threatening disease. Turk J Emerg Med. 2017;17(2):70-2
5. Shin J, Shin PJ, Bartolotta RJ. SMA-like syndrome with variant mesenteric venous anatomy. Clin Imaging. 2018;48:86-9.

6. Goin LS, Wilk SP. Intermittent arteriomesenteric occlusion of the duodenum. Radiology. 1956:67(5):729-37.

7. Catarino Santos S, Loureiro AR, Simao R, Pereira J, Pinheiro LF, Casimiro C. Wilkie's syndrome: a case report of favourable minimally invasive surgery. J Surg Case Rep. 2018;2:rjy027.

8. Michael PG, Al-Saadi T, Jamkhandikar R. A rare case of coexisting superior mesenteric artery syndrome and nutcracker phenomenon. Sultan Qaboos Univ Med J. 2017;17(3):e368-70.

9. Biank V, Werlin S. Superior mesenteric artery syndrome in children: a 20-year experience. J Pediatr Gastroenterol Nutr. 2006;42(5):522-5.

10. Kawanishi K, Shojima K, Nishimoto M, Abe H, Kakimoto T, Yasuda Y, Hara T, Kato J. Superior mesenteric artery syndrome may be overlooked in women with functional dyspepsia. Intern Med. 2017;56(19):2549-54

11. Neri S, Signorelli SS, Mondati E, Pulvirenti D, Campanile E, Di Pino L, Scuderi M, Giustolisi N, Di Prima P, Mauceri B, et al. Ultrasound imaging in diagnosis of superior mesenteric artery syndrome. J Intern Med. 2005;257(4):346-51.

12. Cicero G, D'Angelo T, Bottari A, Costantino G, Visalli C, Racchiusa S, Marino MA, Cavallaro M, Frosina L, Blandino A, et al. Superior mesenteric artery syndrome in patients with Crohn's disease: a description of 2 cases studied with a novel magnetic resonance Enterography (MRE) procedure. Am J Case Reports. 2018;19:431-7.

13. Osegueda de Rodriguez EJ, Hernandez-Villegas AC, Serralde-Zuniga AE, Reyes-Ramirez A. The two sides of superior mesenteric artery syndrome treatment: conservative or surgical management? Nutr Hosp. 2017;34(4):997-1000.

14. Valiathan G, Wani M, Lanker J, Reddy PK. A case series on superior mesenteric artery syndrome surgical management, single institution experience. J Clin Diagn Res. 2017;11(8):PR01-3.

15. Kirby GC, Faulconer ER, Robinson SJ, Perry A, Downing R. Superior mesenteric artery syndrome: a single Centre experience of laparoscopic duodenojejunostomy as the operation of choice. Ann R Coll Surg Engl. 2017;99(6):472-5.

16. Oh MJ. Superior mesenteric artery syndrome combined with renal nutcracker syndrome in a young male: a case report. Korean J Gastroenterol. 2017:70(5):253-60.

17. Takehara K, Sakamoto K, Takahashi R, Kawai M, Kawano S, Munakata S, Sugimoto K, Takahashi M, Kojima Y, Fukunaga T, et al. Superior mesenteric artery syndrome improved by enteral nutritional therapy according to the controlling nutritional status score. Case Rep Gastroenterol. 2017;1 1(3):729-35.

\section{Ready to submit your research? Choose BMC and benefit from:}

- fast, convenient online submission

- thorough peer review by experienced researchers in your field

- rapid publication on acceptance

- support for research data, including large and complex data types

- gold Open Access which fosters wider collaboration and increased citations

- maximum visibility for your research: over $100 \mathrm{M}$ website views per year

At $\mathrm{BMC}$, research is always in progress.

Learn more biomedcentral.com/submission 